\title{
Penyadapan Tanaman Karet (Hevea brasiliensis Mull-Arg.) di Perkebunan Karet Gurach Batu Estate, Asahan, Sumatera Utara
}

Rubber Tapping System ( $\underline{\text { Hevea brasiliensis }}$ Mull-Arg.) at Gurach Batu Estate, Asahan, Sumatera Utara

\author{
Awliya Rahmi Arja dan Supijatno*
}

Departemen Agronomi dan Hortikultura, Fakultas Pertanian, Institut Pertanian Bogor

(Bogor Agricultural University), Jl. Meranti, Kampus IPB Darmaga, Bogor 16680, Indonesia

Telp. \& Faks.62-251-8629353 e-mail agronipb@indo.net.id

*Penulis Korespondensi : supijatno@yahoo.co.id

Disetujui : 15 Januari 2018 / Published Online 23 Januari 2018

\begin{abstract}
The research program was conducted at Gurach Batu Estate, North Sumatera began from Februari 2016 until Juni 2016. This research is aiming to analyze rubber tapping system directly at the field so can improve the technical and management skill. Tapping is a main aspect in rubber plantation so it must be well manage and controlled. Tapping in GBE is not represent the company standard but still in tolerate range. Bark consumption in $d / 3$ and $d / 4$ are $1.3 \mathrm{~mm}$ and $1.6 \mathrm{~mm}$. Tapping depth in $d / 3$ and d/4 are $2.5 \mathrm{~mm}$ and $0.9 \mathrm{~mm}$, its both are out of company standard range. Latex production by A class tapper is more than $B$ class tapper and monthly bark consumption by A class tapper is less than B class tapper. Tapping speed between A class tapper and B class tapper is not significantly different, it's around 16.17 second tree ${ }^{-1}$ and 17.97 second tree ${ }^{-1}$. Stimulant aplication in GBE is in accordance with company standard. Tapping Panel Dryness disease in clone RRIM 921, PB 260 and IRR 118 are 6.6\%, 7.5\%, and $5.75 \%$. There should be a serious act to handle TPD because the disease precentege is high. Tapping supervision in panel B should have done better.
\end{abstract}

Keywords bsp, rubber, stimulant, tapping, tpd

\begin{abstract}
ABSTRAK
Kegiatan penelitian dilaksanakan di Divisi IV Gurach Batu Estate PT Bakrie Sumatera Plantation Tbk Asahan, Sumatera Utara sejak Februari 2016 sampai Juni 2016. Tujuan pelaksanaan penelitian adalah mempelajari dan melakukan kegiatan penyadapan karet untuk meningkatkan keterampilan teknis dan manajerial secara langsung di lapangan. Penyadapan adalah kegiatan utama pada perkebunan karet, maka harus dilakukan dengan manajemen yang baik. Penyadapan di GBE masih belum sesuai dengan standar perusahaan namun masih dalam rentang yang dapat ditoleransi. Rata-rata ketebalan pemakaian kulit sadap ada frekuensi sadap d/4 dan d/3 adalah $1.3 \mathrm{~mm}$ dan $1.6 \mathrm{~mm}$. Rata-rata kedalaman irisan sadap pada sadapan d/4 adalah $2.5 \mathrm{~mm}$ dan pada sadapan d/3 $0.9 \mathrm{~mm}$. Produksi latek yang didapatkan oleh penyadap kelas A lebih banyak dibanding kelas B, dan pemakaian kulit oleh kelas A lebih sedikit dibanding kelas B. Kecepatan menyadap kelas A dan kelas B tidak berbeda nyata yaitu sekitar 16.17 detik pohon ${ }^{-1}$ dan 17.97 detik pohon ${ }^{-1}$. Aplikasi zat stimulan yang dilakukan di Divisi IV GBE telah sesuai dengan aturan dan standar perusahaan. Persentase serangan KAS pada klon RRIM 921, PB 260 dan IRR 118 adalah 6.6\%, 7.5\%, dan $5.75 \%$. Sebaiknya dilakukan penanganan yang lebih serius terhadap serangan KAS di GBE karena tingkat serangan tergolong tinggi. Pengawasan sadapan pada panel B sebaiknya lebih diperhatikan.
\end{abstract}

Kata kunci : bps, karet, KAS, penyadapan, stimulansia 


\section{PENDAHULUAN}

Karet alam adalah salah satu komoditas ekspor andalan Indonesia yang diproduksi tanaman karet (Hevea brasiliesis Muell-Arg). Ekspor karet merupakan salah satu sektor yang selama ini menopang perekonomian Indonesia pasca krisis 1998. Data BPS (2014) menyebutkan bahwa pada tahun 2013 volume ekspor karet alam Indonesia mencapai 2590200 ton dengan total nilai ekspor sebesar US\$ 6.6 milyar. Ekspor karet Indonesia masih dalam bentuk karet remah. Sekitar $85.96 \%$ produksi karet alam Indonesia diekspor ke mancanegara dan hanya sebagian kecil yang dikonsumsi dalam negeri.

Pemenuhan kebutuhan karet dunia sebagian telah tergantikan oleh karet sintetik. Adanya karet sintetik tidak dapat sepenuhnya menggantikan peran karet alam. Beberapa kelebihan karet alam yang tidak dapat dipenuhi oleh karet sintetik adalah elastisitas yang tinggi dan daya lenting sempurna, daya aus yang tinggi, tidak mudah panas dan tahan terhadap keretakan.

Tahun 2012 Indonesia memiliki perkebunan karet seluas 3506201 ha dengan produksi mencapai 3012254 ton dan produktivitas $1073 \mathrm{~kg}$ karet kering $\mathrm{ha}^{-1}$ (Ditjenbun, 2014). Perkebunan karet ini sebagian besar adalah perkebunan rakyat yaitu $85.06 \%$, perkebunan besar milik swasta $7.9 \%$ dan perkebunan milik negara sebesar $6.95 \%$. Perkebunan karet Indonesia masih jauh lebih luas dibandingkan lahan karet Malaysia dan Thailand namun produksi karet Indonesia masih di bawah negara-negara tersebut. Luas perkebuan karet Malaysia adalah $1048 \quad 000$ ha dengan produktivitas $1.494 \mathrm{~kg} \mathrm{ha}^{-1}$ dan luas perkebunan karet Thailand sebesar 2760000 ha dengan produktivitas $1800 \mathrm{~kg} \mathrm{ha}^{-1}$ (ANRPC, 2011).

Kuantitas dan kualitas sadapan di perkebunan karet Indonesia masih rendah, kebun tidak terawat, dan petani karet memiliki pendapatan yang kecil (Kemenperin, 2014). Banyak faktor yang menyebabkan rendahnya produksi karet Indonesia. Faktor-faktor tersebut antara lain: teknik budidaya yang kurang tepat, sistem eksploitasi atau manajemen teknis penyadapan yang belum efisien, penyakit akar dan kering alur sadap yang belum dapat teratasi, dan masih kurangnya pengembangan bibit unggul yang tahan penyakit.

Pelaksanaan teknis penyadapan karet akan berkaitan dengan produktivitas tanaman, umur ekonomis tanaman dan perencanaan produksi untuk periode mendatang. Manajemen penyadapan dapat dilakukan dengan memperhatikan konsumsi kulit sadap, keterampilan tenaga kerja penyadap, dan penggunaan aplikasi zat stimulansia. Konsumsi kulit akan dipengaruhi oleh frekuensi atau intensitas penyadapan, kedalaman irisan, ketebalan irisan dan waktu penyadapan. Bila faktor-faktor tersebut dikombinasikan dengan baik dan dirumuskan dalam bentuk notasi atau sistem eksploitasi yang benar maka akan dapat meningkatkan produktivitas tanaman karet. Tenaga kerja penyadapan pada kelas berbeda memiliki tingkat keterampilan yang berbeda, sehingga jumlah produksi lateks yang dihasilkan juga berbeda (Robianto, 2013). Perkebunan karet Dolok Ulu PT BSRE menempatkan kelas penyadap pada sistem sadap yang berbeda karena akan mempengaruhi produksi dan pemakaian kulit sadapan. Penyadap Kelas A ditempatkan pada sadap tarik $1 / 2 \mathrm{~S}$ d/3 dan penyadap junior pada sistem sadap sorong $1 / 4 \mathrm{~S} d / 3$. Hal ini ditetapkan berdasarkan produksi cuplump yang dihasilkan (Wiguna, 2014).

Harga karet di pasaran dunia (SIR 20) selama 2015 hanya USD $1,2 \mathrm{~kg}^{-1}$ sedangkan harga di tingkat petani adalah Rp 4000.00 - Rp 5500.00 $\mathrm{kg}^{-1}$ karet kering. Harga ini adalah harga paling rendah selama satu dekade terakhir (Gapkindo, 2015). Harga karet 2016 mulai sedikit meningkat yaitu sekitar Rp $7000.00 \mathrm{~kg}^{-1}$ karet kering di tingkat petani (Gapkindo, 2016). Melihat harga karet yang merosot belakangan ini memang tidak dapat dihindari namun harus dihadapi dengan pengaturan manajemen penyadapan yang lebih efisien agar tidak menimbulkan kerugian yang lebih banyak. Apabila kondisi ini dihadapai dengan gegabah tanpa perencanaan yang jelas maka hanya akan menambah kerugian. Penyadapan yang dilakukan sistem eksploitasi tinggi dan aplikasi zat stimulansia akan menyebabkan tingginya penyakit kering alur sadap. Penyadapan yang dilakukan sembarangan akan menghambat peremajaan kulit sadap (Obuayeba et al., 2009).

Menjalankan manajemen penyadapan yang baik akan menjaga kontinuitas produksi karet dan meningkatkan produksi karet pada periode puncaknya. Selain itu, tanaman karet adalah tanaman perkebunan yang umur ekonomisnya cukup panjang mencapai 20 tahun. Harga yang merosot selama dua tahun terakhir seharusnya tidak lantas menyurutkan semangat karena masih akan tertutupi dengan masa produksi yang panjang. Seiring dengan perbaikan kondisi ekonomi masih ada kemungkinan dan peluang bahwa dalam setahun atau dua tahun ke depan harga karet akan kembali membaik.

Pelaksanaan penelitian secara umum bertujuan untuk meningkatkan pemahaman 
terhadap teori melalui kegiatan praktik yang sesungguhnya di lapangan. Tujuan penelitian secara khusus adalah mempelajari dan mengetahui sistem penyadapan tanaman karet di perkebunan karet Gurach Batu Estate, Asahan, Sumatera Utara. Setelah mengikuti pekerjaan sesuai dengan prosedur, dapat meningkatkan keterampilan teknis dan manajerial secara langsung di lapangan.

\section{METODE PENELITIAN}

Kegiatan penelitian ini dilaksanakan di Divisi IV perkebunan karet Gurach Batu Estate, Asahan, Sumatera Utara. Penelitian dilakukan selama empat bulan dimulai sejak Februari 2016 hingga Juni 2016. Kegiatan penelitian dilaksanakan dengan mengikuti serangkaian kegiatan teknis dan manajerial secara umum di perkebunan karet Gurach Batu Estate, Asahan, Sumatera Utara. Kegiatan yang dilaksanakan adalah kegiatan teknis sebagai karyawan harian lepas selama 1.5 bulan dan kegiatan manajerial sebagai pendamping mandor selama 1.5 bulan serta sebagai pendamping asisten divisi selama satu bulan. Kegiatan teknis yang dilaksanakan sebagai Karyawan Harian Lepas (KHL) adalah kegiatan persiapan penyadapan, pemeliharaan TBM dan TM, pengendalian gulma dan penyakit, aplikasi zat stimulansia, penyadapan, pengumpulan lateks dan penimbangan hasil. Kegiatan persiapan penyadapan meliputi sensus pokok, penggambaran bidang sadap, pemasangan alat sadapan, pembagian hanca, dan pembukaan sadapan awal. Kegiatan manajerial yang dilaksanakan sebagai pendamping mandor sadap dan perawatan adalah mengawasi kegiatan kerja, mengecek kehadiran karyawan, dan membuat laporan realisasi pekerjaan harian.

Pengamatan dan pengumpulan data terdiri dari data primer dan data sekunder. Data primer meliputi pengamatan kondisi kulit sadapan, tenaga kerja sadapan, aplikasi stimulansia, dan serangan KAS. Data primer didapatkan dengan pengamatan langsung dikebun yang dilakukan selama magang. Data sekunder yang diperlukan adalah produktivitas tanaman, keadaan tanaman produksi, kelas penyadap di kebun, letak geografis dan administratif, keadaan iklim dan tanah, struktur organisasi dan ketenagakerjaan. Data tersebut didapatkan dari arsip kebun yang terdapat di kantor estate maupun kantor divisi dengan izin petugas.

Pengamatan kondisi kulit sadapan diperoleh dengan mengamati tiga orang tenaga kerja penyadap pada 20 tanaman sampel. Pengamatan dilakukan pada frekuensi penyadapan tiga hari sekali (d/3) dan empat hari sekali (d/4), sadapan panel A dan panel B. Pengamatan diulang tiga kali (tiga hari berturut-turut). Parameter kondisi sadapan yang diamati adalah tinggi alur sadap, lingkar batang, ketebalan pemakaian kulit sadap dan kedalaman irisan dari kambium. Pengamatan lingkar batang, tinggi alur sadap, dan tatal sadap diukur menggunakan meteran sedangkan kedalaman irisan diukur menggunakan jarum inspeksi sadapan. Pengamatan tenaga kerja sadapan dilakukan pada masing-masing kelas penyadap (A dan B) yang telah ditentukan oleh perusahaan. Terdapat lima orang penyadap yang diamati pada masing masing kelas. Hal yang diamati mengenai tenaga kerja penyadapan adalah: jumlah pohon yang dapat disadap, pemakaian kulit sadapan per bulan, kecepatan menyadap, dan hasil sadapan.

Beberapa hal yang diamati mengenai aplikasi zat stimulansia adalah waktu aplikasi, dosis, konsentrasi (pengenceran), cara aplikasi, frekuensi aplikasi, dan zat stimulansia yang dipakai (bahan aktif dan merek dagang). Setelah itu dibandingkan apakah data yang diperoleh di lapangan sesuai dengan aturan dan standar yang telah ditetapkan perusahaan. Pengamatan juga dilakukan terhadap respon hasil produksi lateks setelah aplikasi stimulan pada klon yang ada di Divisi IV GBE. Tanaman yang terserang Kering Alur Sadap (KAS) di kebun diamati secara visual. Pengamatan dilakukan pada tanaman yang bidang sadapannya panel $\mathrm{A}$, panel $\mathrm{B}$ dan panel $\mathrm{H}$. Tanaman sampel yang akan diamati adalah 200 tanaman dari tiap blok yang ditentukan secara acak. Pengamatan dilakukan pada tanaman dengan klon PB 260, RRIM 921, dan IRR 118. Jumlah tanaman yang terserang dibagi jumlah tanaman diamati lalu dinyatakan dalam persen.

Data yang diperoleh dinalisis secara kuantitatif dan kualitatif, mencari rata-rata, mempersentasekan, dan menggunakan uji $t$ student taraf $5 \%$. Data yang diolah diuraikan secara deskriptif dengan membandingkan nilai rataan yang didapat dengan standar perusahaan.

\section{HASIL DAN PEMBAHASAN}

\section{Kondisi Umum}

Lokasi penelitian berada di Divisi IV Gurach Batu Estate yang secara administratif adalah bagian dari Kec. Pulo Bandring, Kabupaten Asahan, Sumatera Utara. Letak kebun GBE secara geografis adalah di $2^{\circ} 57^{\prime}-3^{\circ} 2^{\prime}$ LU dan $99^{\circ} 30^{\prime}-99^{\circ} 35^{\prime}$ BT. Lokasi perkebunan hanya berjarak $\pm 10 \mathrm{~km}$ dari pusat kota Asahan dan 162 $\mathrm{km}$ dari kota Medan. Tipe iklim di GBE berdasarkan klasifikasi Schmidth-Ferguson adalah 
tipe B yang bersifat basah. Curah hujan rata-rata selama 10 tahun terakhir adalah $1620.75 \mathrm{~mm}$ tahun $^{-1}$, hari hujan $98.5 \mathrm{hh} \operatorname{tahun}^{-1}, 2.4$ bulan kering, dan 7.8 bulan basah. Berdasarkan data yang diperoleh dari arsip perusahaan wilayah kebun Gurach Batu Estate berada diketinggian 2438 mdpl dan kemiringan 0-8\%. Jenis tanah di wilayah kebun GBE adalah tanah podsolik merah kuning dengan tekstur tanah liat berpasir dengan pH 4-6.

Sebelum ditanami karet, GBE adalah areal perkebunan tembakau di bawah perusahaan Belanda. Areal tanaman karet yang ada di GBE sekarang adalah tanaman karet yeng sudah diremajakan berkali-kali sejak tahun 1957. Sejak tahun 1993 mulai dilakukan konversi sebagian lahan ke kelapa sawit. Sekarang ini areal yang masih digunakan untuk tanaman karet adalah $71.5 \%$ dari total areal budidaya GBE. Blok tanaman di Divisi IV GBE dibagi berdasarkan tahun tanam dan klon. Tahun 2016 ini ada 24 blok yang terdiri dari berbagai jenis klon yaitu 5 klon prang besar (PB 330, PB340, PB 260, PB 366, PB 314), 1 klon prang merah (PM 10), 2 klon IRR
(IRR 118 dan IRR series), GT1, dan T3601B. Jarak tanam yang digunakan sampai tahun 2005 adalah $5.5 \mathrm{~m} \times 3.8 \mathrm{~m}$ dengan populasi 478 tanaman $\mathrm{ha}^{-1}$. Sejak 2006 sampai sekarang jarak tanam yang digunakan adalah $6.5 \mathrm{~m} \times 3 \mathrm{~m}$ dengan populasi 512 tanaman $\mathrm{ha}^{-1}$. Sebagian besar tanaman karet yang ada di Divisi IV GBE adalah tanaman menghasilkan yaitu seluas 876 ha. Sedangkan tanaman belum menghasilkan hanya seluas 1 ha. Sejak 2010 belum ada program peremajaan tanaman karet di divisi IV GBE.

Produksi tanaman karet di Gurach Batu Estate dari tahun 2010-2016 mengalami peningkatan, Hal ini disebabkan oleh bertambahnya luas areal TM selama tahun 2015 sebanyak 87 ha dan tidak ada TM yang direplanting. Namun produktivitas tanaman per tahun tidak selalu meningkat. Produktivitas tanaman karet per tahun pada tahun 2014 adalah 1 $653.3 \mathrm{~kg} \mathrm{ha}^{-1}$ dan pada tahun 2015 turun menjadi $1602.34 \mathrm{~kg} \mathrm{ha}{ }^{-1}$. Angka produksi dan produktivitas tanaman karet Gurach Batu Estate selama 5 tahun terakhir dapat dilihat pada Tabel 1

Tabel 1. Produk dan produktivitas karet GBE tahun 2011-2015

\begin{tabular}{cccc}
\hline Tahun & $\begin{array}{c}\text { Luas lahan TM } \\
(\text { ha })\end{array}$ & $\begin{array}{c}\text { Produksi } \\
(\mathrm{kg})\end{array}$ & $\begin{array}{c}\text { Produktivitas per tahun } \\
\left(\mathrm{kg} \mathrm{ha}^{-1}\right)\end{array}$ \\
\hline 2011 & 1909 & 3269542 & 1712.70 \\
2012 & 2124 & 3345805 & 1575.24 \\
2013 & 2311 & 3625119 & 1568.64 \\
2014 & 2367 & 3913497 & 1653.36 \\
2015 & 2454 & 3932166 & 1602.34 \\
\hline
\end{tabular}

Produktivitas karet di GBE masih lebih tinggi bila dibandingkan dengan rata-rata produktivitas perkebunan karet indonesia. Produktivitas karet nasional tahun 2014 adalah 1 $036 \mathrm{~kg} \mathrm{ha}^{-1}$ dan produktivitas perkebunan swasta adalah 2014 adalah $1514 \mathrm{~kg} \mathrm{ha}^{-1}$ (Ditjenbun, 2014). Bila dibandingkann dengan perusahaan swata lain seperti PT BSRE dan tulung gelam estate PT PP London Sumatera Indonesia, produktivitas karet di GBE relatif setara. Produktivitas PT BSRE tahun 2012 adalah 1599 $\mathrm{kg} \mathrm{ha}^{-1}$ (Wiguna, 2014). Produktvitas tanaman karet di TGE PT PP London Sumatera adalah sebesar $1.097 \mathrm{~kg} \mathrm{ha}^{-1}$ (Robianto, 2013).

\section{Kondisi Kulit Sadapan}

Tinggi alur sadap, kedalaman irisan sadap, ketebalan sadapan, dan lilit batang adalah beberapa hal yang mempengaruhi produksi dan umur ekonomis tanaman karet. Irisan sadap yang terlalu dalam dan pemakaian kulit yang terlalu tebal merupakan suatu pemborosan dan dianggap sebagai losses, bila irisan sadap terlalu dangkal dapat menyebabkan luka kayu dan akan berdampak pada produksi berikutnya. Menurut standar perusahaan PT BSP, kedalaman irisan sadap untuk sadap bawah adalah 1-1.5 mm sedangkan ketebalan sadapan untuk sekali sadap adalah 1.3-1.5 mm. Kondisi kulit sadapan berdasarkan frekuensi penyadapan dapat dilihat pada Tabel 2. 
Tabel 2. Kondisi kulit sadapan berdasarkan frekuensi penyadapan

\begin{tabular}{cccccc}
\hline $\begin{array}{c}\text { Frekuensi } \\
\text { sadap }\end{array}$ & Penyadap & $\begin{array}{c}\text { Tinggi alur sadap } \\
(\mathrm{cm})\end{array}$ & $\begin{array}{c}\text { Lilit batang } \\
(\mathrm{cm})\end{array}$ & $\begin{array}{c}\text { Ketebalan } \\
\text { sadapan }(\mathrm{mm})\end{array}$ & $\begin{array}{c}\text { Kedalaman irisan } \\
(\mathrm{mm})\end{array}$ \\
\hline $\mathrm{d} / 4$ & 1 & 116.0 & 51.9 & 1.3 & 2.7 \\
& 2 & 116.6 & 52.3 & 1.2 & 2.3 \\
& 3 & 116.4 & 52.0 & 1.5 & 2.6 \\
\hline Rata-rata & $116.4 \mathrm{a}$ & $52.1 \mathrm{~b}$ & $1.3 \mathrm{~b}$ & $2.5 \mathrm{a}$ \\
\hline $\mathrm{d} / 3$ & 1 & 87.1 & 65.5 & 1.7 & 0.8 \\
& 2 & 84.4 & 66.1 & 1.5 & 0.8 \\
& 3 & 86.0 & 65.3 & 1.8 & $0.9 \mathrm{~b}$ \\
\hline Rata-rata & & $85.8 \mathrm{~b}$ & $65.6 \mathrm{a}$ & $1.6 \mathrm{a}$ & 0 \\
\hline
\end{tabular}

Keterangan : angka diikuti huruf yang sama pada kolom yang sama tidak berbeda nyata berdasarkan uji $t$-student taraf $5 \%$

Tabel 2 menunjukkan bahwa kondisi kulit sadapan dengan $d / 4$ dan $d / 3$ berbeda nyata berdasarkan uji $t$-student $5 \%$. Tinggi alur sadap dan lilit batang berbeda nyata, karena sistem sadap d/4 diterapkan pada tanaman TM 1- TM 2 dan sistem sadap d/3 adalah pada TM 3-TM 15. Tinggi alur sadap akan berkurang seiring bertambahnya umur tanaman sehingga tingg alur sadap $\mathrm{d} / 3$ lebih rendah dibanding alur sadap $\mathrm{d} / 4$.

Rata-rata ketebalan pemakaian kulit pada sadapan $\mathrm{d} / 4$ adalah $1.3 \mathrm{~mm}$ dan pada sadapan $\mathrm{d} / 4$ $1.6 \mathrm{~mm}$. Rata-rata kedalaman irisan sadap pada sadapan d/4 adalah $2.5 \mathrm{~mm}$ dan pada sadapan $\mathrm{d} / 3$
$0.9 \mathrm{~mm}$. Ketebalan pemakaian kulit sadapan d/4 masih sesuai dengan aturan sadapan perusahaan sedangkan pada sadapan $\mathrm{d} / 3$ sedikit melebihi standar. Irisan sadap pada sadapan $\mathrm{d} / 4$ terlalu dalam bila dibandingkan dengan aturan perusahaan, sedangkan sadapan $\mathrm{d} / 3$ sedikit kurang dari standar. Penyadapan yang ditaruh pada sadapan $\mathrm{d} / 4$ cenderung agak berhati-hati saat penyadapan karena masih TM 1 dan TM 2 sehingga kedalaman irisannya terlalu tebal dan sangat jarang ditemui luka kayu. Kondisi kulit sadapan berdasarkan panel sadap dapat dilihat pada Tabel 3.

Tabel 3. Kondisi kulit sadapan berdasarkan panel sadap

\begin{tabular}{|c|c|c|c|c|c|}
\hline $\begin{array}{c}\text { Tapping } \\
\text { frekuensi } \\
\text { (tahun tanam) }\end{array}$ & Penyadap & $\begin{array}{l}\text { Tinggi alur sadap } \\
\qquad(\mathrm{cm})\end{array}$ & $\begin{array}{l}\text { Lilit batang } \\
\quad(\mathrm{cm})\end{array}$ & $\begin{array}{l}\text { Ketebalan sadapan } \\
\qquad(\mathrm{mm})\end{array}$ & $\begin{array}{c}\text { Kedalaman } \\
\text { irisan } \\
(\mathrm{mm}) \\
\end{array}$ \\
\hline Panel A & 1 & 87.1 & 65.5 & 1.7 & 0,8 \\
\hline \multirow[t]{2}{*}{ (2008) } & 2 & 84.4 & 66.1 & 1.5 & 0,8 \\
\hline & 3 & 86.0 & 65.3 & 1.8 & 1,0 \\
\hline \multicolumn{2}{|c|}{ Rata-rata } & $85.8 \mathrm{a}$ & $65.6 \mathrm{~b}$ & $1.6 \mathrm{a}$ & $0.9 \mathrm{a}$ \\
\hline Panel B & 1 & 71.7 & 73.2 & 1.6 & 0,7 \\
\hline \multirow[t]{2}{*}{ (2003) } & 2 & 69.5 & 71.6 & 1.5 & 0,8 \\
\hline & 3 & 68.5 & 68.8 & 1.6 & 0,9 \\
\hline \multicolumn{2}{|c|}{ Rata-rata } & $69.9 b$ & $71.2 \mathrm{a}$ & $1.5 \mathrm{a}$ & $0.8 \mathrm{a}$ \\
\hline
\end{tabular}

Keterangan : angka diikuti huruf yang sama pada kolom yang sama tidak berbeda nyata berdasarkan uji $t$-student taraf $5 \%$

Kondisi kulit sadapan di panel A dan panel B menunjukkan bahwa lilit batang dan tinggi alur sadapnya berbeda nyata namun ketebalan sadapan dan kedalaman irisan tidak berbeda nyata. Rata-rata ketebalan pemakaian kulit sadap pada panel A adalah $1.6 \mathrm{~mm}$ dan pada panel B $1.5 \mathrm{~mm}$, angka ini sedikit melebihi standar perusahaan. Rata-rata kedalaman irisan sadap pada panel A adalah $0.9 \mathrm{~mm}$ dan panel B $0.8 \mathrm{~mm}$. Kedalaman irisan sadapan kurang dari standar perusahaan yaitu $1 \mathrm{~mm}-1.5 \mathrm{~mm}$.
Kondisi kulit sadapan dan kualitas penyadapan harus dijaga dengan baik agar kulit karet dapat tetap berproduksi dan memperpanjang umur ekonomisnya. Mathurin et al. (2016) menyatakan bahwa, konsumsi kulit yang terlalu tinggi, penyadapan yang terlalu dalam, banyak kelukaan pada kulit, dan frekuensi penyadapan yang tinggi menyebabkan stres pada tanaman karet secara fisiologis. 


\section{Tenaga Kerja Penyadap}

Kelas penyadap sangat perlu ditentukan untuk menjaga mutu dan kualitas sadapan. Penyadapan yang baik akan menjaga kulit dan bidang sadap sehingga dapat dipakai selama 20 tahun sesuai yang direncanakan perusahaan. Kecepatan menyadap, pemakaian kulit per bulan, dan hasil sadapan oleh penyadap kelas A dan kelas B dapat dilihat pada Tabel 4.

Tabel 4. Kecepatan sadap, pemakaian kulit, dan hasil sadapan penyadap berdasarkan kelas

\begin{tabular}{ccccc}
\hline Kelas penyadap & $\mathrm{n}$ & $\begin{array}{c}\text { Kecepatan menyadap } \\
\left(\text { detik pohon }^{-1}\right)\end{array}$ & $\begin{array}{c}\text { Pemakaian kulit per } \\
\text { bulan }(\mathrm{cm})\end{array}$ & $\begin{array}{c}\text { Hasil sadapan } \\
(\mathrm{kg})\end{array}$ \\
\hline $\mathrm{A}$ & 15 & $16.17 \pm 1.35$ & $1.6 \pm 0.2$ & $45.00 \pm 5.33$ \\
$\mathrm{~B}$ & 15 & $17.97 \pm 1.69$ & $1.8 \pm 0.2$ & $37.80 \pm 4.65$ \\
p-Value & & $0.003^{\text {tn }}$ & $0.000^{* *}$ & $0.001^{*}$ \\
\hline Keterangan : * berbeda nyata, ** sangat nyata, ${ }^{\text {tn }}$ tidak berbeda nyata &
\end{tabular}

Tabel 4 menunjukkan bahwa penyadap kelas A dan kelas B memperoleh rata-rata hasil sadapan yang berbeda nyata. Rata-rata hasil sadapan per hari yang oleh penyadap kelas A adalah $45 \mathrm{~kg}$ dan penyadap kelas B adalah 38.8 $\mathrm{kg}$. Kelas penyadap dibedakan berdasarkan keterampilan menyadap yang benar dan sesuai aturan perusahaan. Keterampilan menyadap akan mempengaruhi hasil sadapan. Faktor yang mempengaruhi adalah kedalaman sadapan dan pemakaian kulit. Kedalaman sadapan yang terlalu tebal dari kambium membuat hasil sadapan tidak maksimal karena hanya sebagian pembuluh yang tersayat sehingga lateks yang dikeluarkanpun tidak maksimal. Penyadapan yang terlalu dalam hingga ke lapisan kayunya maka pembuluh lateks akan terputus dan membutuhkan waktu lebih lama untuk pemulihan. Selain itu, bila penyadapan menyebabkan banyak luka kayu maka kulit pulihan akan membentuk benjolan yang tidak rata. Kecepatan menyadap kelas A dan kelas B tidak menunjukkan perbedaan yang nyata. Ratarata kecepatan menyadap pada kelas A adalah 16.17 detik per pohon dan kelas B adalah 17.97 detik per pohon. Pengamatan terhadap kecepatan menyadap dilakukan karena akan mempengaruhi waktu tunggu mengalirnya lateks sebelum dipungut. Jam kerja penyadapan di GBE hanya dilakukan jam 06.00-13.00 dengan hitungan 7 jam kerja. Lain halnya di PT Bridgestone Sumatera Rubber Estate yang penyadapannya dilakukan sampai jam 5 sore dengan hitungan lembur sehingga memungkinkan lateks mengalir lebih lama sampai akhirnya berhenti karena penggumpalan (Wiguna, 2013). Bila penyadap lebih cepat menyelesaikan hancanya maka diharapkan waktu tunggu sebelum pengumpulan lateks lebih lama. Walaupun lateks yang tertampung setelah pemungutan masih akan diambil besok harinya dalam bentuk cuplump, namun produksi utama dari GBE adalah lateks karena akan diolah menjadi lateks konsentrat dan SIR.

Peningkatan produksi tanaman karet di perusahaan swasta selain dipengaruhi aspek teknis penyadapan juga dipengaruhi oleh aspek non teknis seperti manajemen penyadapan. Manajemen penyadapan dengan pengkelasan penyadap dan sistem premi adalah cara untuk memacu produksi penyadap. Premi GBE adalah premi dasar, premi progresif, premi bonus dan premi sadap hari libur.

\section{Aplikasi Zat Stimulansia}

Aplikasi zat stimulansia yang dilakukan di GBE telah disesuaikan dengan aturan dan standar perusahaan. Respon dari aplikasi zat stimulan pada tiap klon menunjukkan hasil yang berbeda. Persentase peningkatan hasil pada klon PB, IRR dan GT-1 akan lebih melonjak pada penyadapan kedua setelah aplikasi yaitu sebesar $57.8 \%$ pada klon PB, 55.5\% pada klon IRR dan $65.5 \%$ pada klon GT-1. Peningkatan hasil pada klon RRIC paling tinggi adalah saat penyadapan pertama setelah aplikasi sebesar $36 \%$, lalu cenderung menurun pada penyadapan kedua dan ketiga. Klon RRIM menunjukkan peningkatan hasil sebesar $47.2 \%$ dan cenderung stabil pada penyadapan berikutnya. Respon peningkatan hasil produksi dapat dilihat pada Gambar 1.

Perbedaan respon peningkatan hasil ini dapat menjadi pertimbangan dalam jadwal aplikasi stimulan berikutnya sehingga dapat menekan biaya produksi dan menghindari over eksploitasi. Aplikasi ulang stimulan pada klon RRIC setelah penyadapan ke-4 mungkin dapat segera dilakukan karena produksi sudah menurun sejak penyadapan ke-2. Klon RRIM, PB, IRR dan GT-1 aplikasi ulang dapat dilakukan setelah produksi sudah mulai turun pada penyadapan ke-5 atau penyadapan ke-6. 


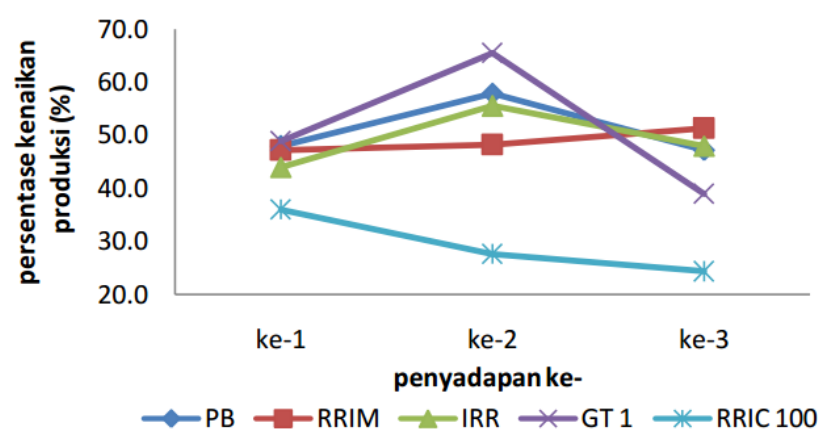

Gambar 1. Respon produksi lateks setelah aplikasi stimulan pada beberapa klon

Zat stimulan dapat meningkatkan produksi lateks melalui beberapa cara yaitu meningkatkan permeabilitas membran, mengakselerasi metabolisme sukrosa, memperpanjang waktu pengaliran lateks, dan memodulasi aktivitas enzim seperti glutamine synthase dan HGMS (Zhu dan Zhang, 2009). Namun aplikasi stimulan harus disesuaikan dengan karakter klon dan intensitas aplikasinya. Menurut Boerhendy (2013) aplikasi stimulan pada klon karet IRR 39 dapat meningkatkan produksi hingga $123 \%$ bila diaplikasikan sejak awal penyadapan dengan notasi sadap $1 / 2 \mathrm{~S} d / 3+$ ET $2 \%$.

\section{Tanaman yang Terserang Kering Alur Sadap}

Keringnya alur sadapan adalah penyakit fisiologis yang terjadi karena eksploitasi yang tinggi dan tidak seimbang dengan metabolisme karet untuk menghasilkan lateks. Gambar 2 menunjukkan bahwa tanaman yang terserang kering alur sadap lebih banyak pada penel sadap B. Tanaman dengan panel sadap B umurnya tentu lebih tua dibandingkan panel $\mathrm{A}$ dan telah berulangkali diberi stimulan. Persentase serangan KAS pada klon RRIM 921 adalah 3\% pada panel A, $6.5 \%$ pada panel B, dan $10.5 \%$ pada panel $\mathrm{H}$. Persentase tanaman yang terserang KAS pada klon PB 260 adalah 6.5\% pada panel A, 7\% pada panel B, dan 9\% pada panel $\mathrm{H}$. Persentase serangan KAS pada klon IRR 118 adalah 5\% pada panel A dan $6.5 \%$ pada panel B. Persentase KAS pada panel H Klon IRR 118 tidak dapat diamati karena di Divisi IV GBE tidak ada blok tanaman IRR dengan panel sadap $\mathrm{H}$.

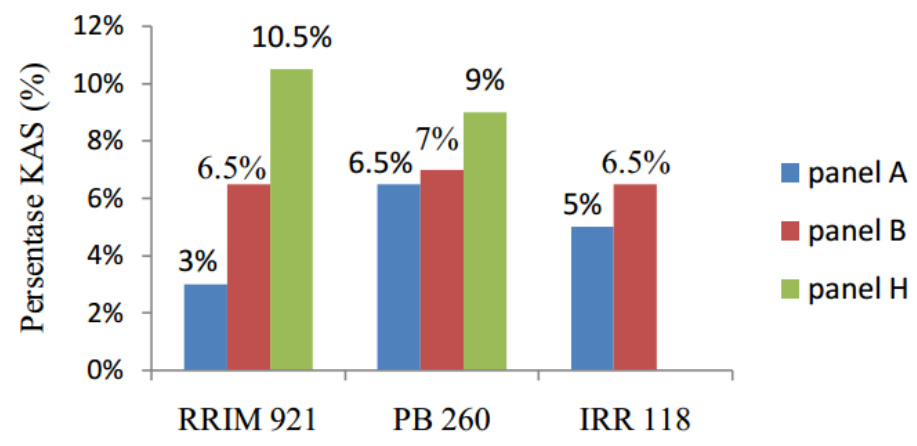

Gambar 2. Persentase tanaman yang terserang KAS pada beberapa klon

Tingkat serangan KAS yang ada di Divisi 4 GBE dapat digolongkan tinggi karena menurut Mochlisin (2014), tingkat serangan KAS tinggi pada klon quick starter adalah $9.2 \%$ dan $7.3 \%$ untuk klon slow starter. Hasil pengamatan serangan KAS ada yang mencapai $10.5 \%$. Bila dibandingkan dengan serangan yang ada di perkebunan swasta lainnya tingkat serangan di BSP tergolong lebih tinggi karena tingkat serangan KAS di Tulung Gelam Estate pada tanaman tahun 2006 (panel A4) adalah sebesar $5.62 \%$ (Robianto, 2013). Wiguna (2014) melaporkan bahwa di PT Bridgeston Sumatera Rubber Estate tingkat serangan pada klon quick starter hanya sebesar $4.09 \%$ dan pada klon slow starter $1.97 \%$.

Tanaman yang terserang KAS di GBE diistirahatkan penyadapannya selama 6 bulan. 
Tanaman yang terserang diberi tanda BB dengan kapur hitam. Untuk mencegah terjadinya KAS tindakan preventif yang dapat dilakukan adalah menetapkan sistem sadap yang baik dan benar, pemakaian stimulansia yang sesuai aturan dan menghindari terjadinya luka kayu. Pemakaian stimulan seperti etepon dapat mendorong terjadinya KAS karena etepon mengeluarkan etilen untuk meninginduksi fungsi sel lateks termasuk produksi senyawa reactive oxygen species (ROS), akumulasi ROS akan menyebabkan penggumpalan pertikel karet dalam sel lateks (Putranto et al., 2015). Menurut Andriyanto dan Tistama (2014), luka kayu merupakan salah satu penyebab terjadinya KAS karena merusak dan memutus pembuluh lateks sehingga aliran lateks menjadi terganggu.

\section{KESIMPULAN}

Kegiatan penelitian yang telah dilakukan dapat meningkatkan keterampilan teknis dan manajerial penulis. Penyadapan yang dilakukan di Divisi IV GBE kurang sesuai dengan standar perusahan namun masih dalam rentang yang bisa ditoleransi. Rata-rata ketebalan pemakaian kulit pada sadapan $\mathrm{d} / 4$ dan $\mathrm{d} / 3$ adalah $1.3 \mathrm{~mm}$ dan 1.6 $\mathrm{mm}$. Rata-rata kedalaman irisan sadap pada sadapan $\mathrm{d} / 4$ adalah $2,5 \mathrm{~mm}$ dan pada sadapan $\mathrm{d} / 3$ $0.9 \mathrm{~mm}$. Rata-rata ketebalan pemakaian kulit dan kedalaman irisan pada sadapan Panel A dan Panel B tidak berbeda nyata. Produksi latek yang didapatkan oleh penyadap kelas A lebih banyak dibanding kelas B, dan pemakaian kulit oleh kelas A lebih sedikit dibanding kelas B. Kecepatan menyadap kelas A dan kelas B tidak berbeda nyata yaitu sekitar 16.17 detik pohon $^{-1}$ dan 17.99 detik pohon ${ }^{-1}$. Aplikasi zat stimulan yang dilakuka di Divisi IV GBE telah sesuai dengan aturan dan standar perusahaan. Respon produksi zat stimulan pada klon IRR, RRIM, dan PB menunjukkan persentase peningkatan produksi yang lebih tinggi pada penyadapan kedua setelah aplikasi. Sedangkan klon RRIC peningkatan produksi hanya pada penyadapan pertama setelah aplikasi. Persentase serangan KAS pada klon RRIM 921, PB 260 dan IRR 118 adalah $6.6 \%$, 7.5\%, dan $5.75 \%$.

\section{DAFTAR PUSTAKA}

Andriyanto, M., Tistama, R.2014.Perkembangan dan upaya pengendalian kering alur sadap (KAS) pada tanaman karet (Hevea brasiliensis). Warta Perkaretan. 33(2):89102.
[ANRPC] Association of Natural Rubber Producing Countries .2011. [internet]. [diunduh 2016 Jan 20]. Tersedia pada Member country info http://anrpc.org.

Boerhendy, I.2013. Penggunaan stimulan sejak awal penyadapan untuk meningkatkan produksi klon IRR 39. Jurnal Penelitian Karet. 31(2):117-126

[BPS] Badan Pusat Statistik. 2012. Statistik karet Indonesia 2011. [internet]. [diunduh 2016 August 08]. Tersedia pada http://www.bps.go.id.

[Ditjenbun] Direktorat Jendral Perkebunan. 2014. Statistik Perkebunan Karet Indonesia 2013-2011 Kementrian Pertanian. Jakarta.

[Gapkindo] Gabungan Petani Karet Indonesia.2015. Analisis pasar Desember 2015. Info Karet 12:1-7.

[Gapkindo] Gabungan Petani Karet Indonesia. 2016. Analisis pasar Juni 2016. Info Karet 6: $1-8$.

[Kemenperin] Kementrian Perindustrian.2014. Produktivitas karet nasional alah dari Malaysia dan Thailand. [internet]. [diunduh 201622 Sept 22]. Tersedia pada http://www.kemenperin.go.id/artikel/734.

Mathurin, O.K., Kuadiou, D., Francis, S.E., Angeline, E.A., Sekou, D., Obuayeba, S., Jules, K.Z. Agricultural practices in Cote' D'Ivoire andappariton and development of tapping panel dryness in (Hevea brasiliensis Muell. Arg.). International Journal of current agricultural sciences 6(7):74-80.

Obuayeba, S., Coulibay, L.F., Gohet, E., Yao, T.N., Ake, S.2009. Effect of tapping system and height of tapping opening on clone PB 235 agronomic parameters and its susceptibility to tapping panel dryness in south east of Cote d'Ivoire'.J. Appl. Biosci. 24:1535-15542.

Putranto, R.A., Herlinawati, E., Rio, M., Leclercq, J., Piyatrakul, P., Gohet E., Sanier C., Oktavia F., Pirello J., Kuswanhadi, Muntoro P. 2015. Involvement of ethylene in latex metabolism and tapping panel dryness on Hevea brasiliensis.Int. J. Mol. Sci. 16: 17885-17908. 
Robianto.2013. Sistem penyadapan karet [Hevea brasilliensis Muell Arg.] di Tulung Gelam Estate, PT PP London Sumatera Indonesia, tbk. Kabupaten Ogan Komering Ilir, Sumatera Selatan.[ Skripsi]. Institut Pertanian Bogor. Bogor.

Wiguna, H.2014. Manajemen penyadapan karet (Hevea Brasiliensis Muell. Arg.) di Dolok
Merangir Estate, PT Bridgestone Sumatra Rubber Estate, Simalungun, Sumatera Utara. [Skripsi]. Fakultas Pertanian. Institut Pertanian Bogor. Bogor.

Zhu, J., Zhang, Z. 2009. Ethylene stimulation of latex productiom in Hevea brasiliensi. Plant Signaling \& behaviour. 4(11):10721074. 